\title{
Elf3 plays a role in regulating bronchiolar epithelial repair kinetics following Clara cell-specific injury
}

\author{
Jordan R Oliver ${ }^{1,2}$, Rahul Kushwah ${ }^{1,2}$, Jing Wư ${ }^{2}$, Jie Pan ${ }^{3}$, Ernest Cutz ${ }^{1,3}$, Herman Yeger ${ }^{1,3}$, Thomas K Waddell ${ }^{4}$ \\ and $\operatorname{Jim~} \mathrm{Hu}^{1,2}$
}

E74-like transcription factor-3 (Elf3), a member of the E26 transformation-specific transcription factor family, is strongly expressed in epithelial-rich tissues, such as small intestine, fetal lung, and various lung cancers. Although previous studies have shown a defect in terminal differentiation of the small intestinal epithelium of Elf3-deficient (Elf3-/-) mice during embryonic development, very little is known about the role Elf3 may play in repair of the airway epithelium after injury. In order to investigate whether Elf3 is involved in regeneration of the bronchiolar epithelium after Clara cell-specific injury, we administered naphthalene to both wild-type $(E l f 3+/+)$ and Elf3 $-/-$ mice. Histopathological analysis revealed no significant difference in the extent of naphthalene-induced Clara cell necrosis between Elf $3+/+$ mice and Elf3-/mice. In the bronchiolar epithelium of Elf3-/- mice, there was a substantial delay in the kinetics of cell proliferation and mitosis along with Clara cell renewal, whereas in the peribronchiolar interstitium, there was a significantly greater level of cell proliferation and mitosis in Elf3-/- mice than in Elf3 $+/+$ mice. Last, the intensity of immunopositive signal for transforming growth factor- $\beta$ type II receptor, which is a well-known transcriptional target gene of Elf 3 and involved in the induction of epithelial cell differentiation, was significantly lower in the bronchiolar epithelium of Elf3-/- mice when compared with Elf3 $+/+$ mice. Taken together, our results suggest that Elf3 plays an important role in the regulation of lung cell proliferation and differentiation during repair of the injured bronchiolar airway epithelium. Laboratory Investigation (2011) 91, 1514-1529; doi:10.1038/labinvest.2011.100; published online 27 June 2011

KEYWORDS: Elf3; epithelial injury; epithelial repair; ETS; transcription factor

Many respiratory disorders, such as asthma and cystic fibrosis, involve airway inflammation and epithelial injury. Subsequent regeneration and repair of the lung epithelium is a vital process to help maintain the function and integrity of the airways. Many laboratories have used naphthalene treatment in experimental animals, which causes Clara cellspecific injury, as a model to study the molecular and cellular mechanisms of airway epithelial regeneration. After treatment with naphthalene, injured and necrotic Clara cells are replaced by other airway epithelial cells, which undergo dynamic changes in cell migration, proliferation, and differentiation. ${ }^{1}$ Many different cell types have been shown to be involved in the process of airway epithelial regeneration following naphthalene-induced Clara cell ablation in mice, and those identified to date include: basal cells, ${ }^{2,3}$ pulmonary neuroendocrine cells, ${ }^{4-6}$ bronchioalveolar stem cells, ${ }^{7,8}$ ciliated cells, ${ }^{9,10}$ peribronchiolar interstitial cells, ${ }^{11,12}$ and a pollutant-resistant sub-population of Clara cells that retain their expression of Clara cell $10-\mathrm{kDa}$ secretory protein (CC10/CCSP), also known as variant CC10/CCSP-expressing (vCE) stem cells. ${ }^{13-15}$ However, the role of various transcription factors in regulating the process of airway epithelial regeneration requires further investigation.

E74-like transcription factor-3 (Elf3) is a member of the E26 transformation-specific (ETS) transcription factor family, which is characterized by a highly conserved DNAbinding domain, known as the ETS domain. ${ }^{16}$ The ETS domain is usually located within the carboxyl-terminal region of the protein and mediates binding to sites of purinerich DNA, commonly containing a core consensus sequence of GGAA/T within the promoter and enhancer regions of target genes. ${ }^{16}$ Many ETS transcription factors also contain a

\footnotetext{
'Department of Laboratory Medicine and Pathobiology, University of Toronto, Toronto, ON, Canada; ${ }^{2}$ Physiology and Experimental Medicine Research Program, The Hospital for Sick Children, Toronto, ON, Canada; ${ }^{3}$ Division of Pathology, Department of Paediatric Laboratory Medicine, The Hospital for Sick Children, Toronto, ON Canada and ${ }^{4}$ Division of Thoracic Surgery, Latner Thoracic Surgery Research Laboratories, Toronto General Hospital, Toronto, ON, Canada

Correspondence: Dr J Hu, PhD, Physiology and Experimental Medicine Research Program, The Hospital for Sick Children, 555 University Avenue, Toronto, ON, Canada M5G1X8.

E-mail: jim.hu@utoronto.ca

Received 10 January 2011; revised 13 May 2011; accepted 13 May 2011
} 
pointed domain, which is located within the amino-terminal region and is involved in protein-protein interactions. ${ }^{16}$ Approximately 30 members of the ETS transcription factor family have been identified in mammals, ${ }^{16}$ and have been shown to play crucial roles in the regulation of many physiological and pathological processes, such as embryonic development, ${ }^{17}$ neoplasia, ${ }^{18}$ hematopoiesis, ${ }^{19}$ angiogenesis, ${ }^{20}$ and inflammation. ${ }^{21}$ Although many ETS family members are expressed in nonepithelial cells, such as hematopoietic and endothelial cells, Elf3 belongs to the epithelium-specific ETS (ESE) subfamily of ETS transcription factors, which are expressed only in epithelial-rich tissues, such as stomach, small intestine, colon, pancreas, trachea, lung, kidney, salivary gland, prostate gland, mammary gland, uterus, and skin. ${ }^{22,23}$ Previous analysis of Elf3 expression in adult mouse tissues has shown the highest expression to occur in small intestine, colon, and uterus. ${ }^{22}$ Very little to no expression of Elf3 was detected in many epithelial-poor tissues, such as spleen, thymus, brain, heart, and skeletal muscle. ${ }^{22,23}$ Similar patterns of expression of the human homolog for the murine Elf3 gene, ESE-1, have also been demonstrated in human tissues. $^{22,23}$ It is also worthy to note that although Elf3 is believed to be expressed exclusively in epithelial cells, this may only be the case under basal conditions as previous studies have shown that expression of human ESE-1 can be induced by proinflammatory cytokines in nonepithelial cells, such as synovial fibroblasts, chondrocytes, osteoblasts, monocytes/macrophages, vascular smooth muscle cells, and endothelial cells. $^{24,25}$

Interestingly, expression of human ESE-1 was also shown to occur in some lung cancers, such as large cell carcinoma and adenocarcinoma, and in lung cancer-derived cell lines, such as A549. ${ }^{22}$ In addition, even though low levels of Elf3 expression were detected in adult mouse lung, very high levels of expression were reported in developing fetal mouse lung. $^{22}$ Although low expression levels for Elf3 have previously been observed in adult mouse lung, this may only be the case under basal conditions as our quantitative real-time RT-PCR analysis of Elf3 mRNA expression in cultured primary airway epithelial cells isolated from adult mouse lung has shown that expression of Elf3 can be significantly induced after stimulation with proinflammatory cytokines (Kushwah et al. unpublished data).

Mice with a null mutation of Elf3 have been previously generated through targeted gene disruption, and $\sim 30 \%$ of the resultant homozygous mutant mice die in utero at around embryonic day $11.5,{ }^{26}$ indicating that there is a role for Elf3 in embryonic/fetal development. Furthermore, many of the Elf3-deficient (Elf3-/-) progeny that do survive to birth eventually develop a 'wasting syndrome' that is characterized by a malnourished physical appearance, watery diarrhea, and lethargy. ${ }^{26}$ Most importantly, Elf3-/- mice exhibit a distinct phenotype in the small intestine during fetal/neonatal development that includes severe morphological alterations in tissue architecture manifested by poor villus formation with improper morphogenesis of the microvilli and defective terminal differentiation of absorptive enterocytes and mucussecreting goblet cells. ${ }^{26}$ Moreover, Elf3-/- enterocytes express reduced protein levels of transforming growth factor$\beta$ type II receptor (TGF- $\beta$ RII), which is a potent inhibitor of cell proliferation and an inducer of epithelial cell differentiation. ${ }^{26}$ Indeed, many in vitro studies have also established that the TGF- $\beta$ RII gene is a definite target of Elf3, and that Elf3 transactivates the TGF- $\beta$ RII gene promoter by binding to two adjacent ETS-binding sites. ${ }^{27-29}$ Interestingly, ectopic expression of the human TGF- $\beta$ RII transgene specifically in the intestinal epithelium of Elf3-/- mice can rescue the previously characterized intestinal defects of Elf3-I- mice. ${ }^{30}$ This phenotypic rescue provides further in vivo evidence that Elf3 is the critical upstream regulator of TGF- $\beta$ RII expression in the mouse small intestinal epithelium. ${ }^{30}$ In addition, we have previously shown reduced expression of the proinflammatory cytokine, interleukin-6 (IL-6), in the lungs of Elf3-/- mice when compared with their wild-type littermates after intranasal instillation of lipopolysaccharide, ${ }^{31}$ suggesting a possible role for Elf3 in the regulation of IL- 6 expression. Both TGF- $\beta$ RII (see Zhao et $a l^{32}$ ) and IL-6 (see Kida et $a l^{33}$ ) have also been shown to be involved in the process of lung injury and repair.

As Elf3 is an epithelial-specific transcription factor that is highly expressed during fetal lung development and plays a role in the regulation of TGF- $\beta$ RII and IL- 6 expression, we sought to investigate whether Elf3 is involved in repair of the bronchiolar airway epithelium after naphthalene-induced Clara cell injury. In the present study, we found that the kinetics of bronchiolar epithelial cell regeneration is delayed in Elf3-/- mice when compared with their wild-type counterparts. We also show that Elf3-/- mice express substantially reduced levels of TGF- $\beta$ RII in the bronchiolar epithelium both basally and during repair after naphthalene treatment. Thus, Elf3 may play an important role as a transcription factor regulating the expression of certain genes that are involved in controlling the kinetics of epithelial cell proliferation and differentiation during the process of lung regeneration.

\section{MATERIALS AND METHODS \\ Animals and Treatments}

Mice with a null mutation of Elf3 were previously generated on a $\mathrm{C} 57 \mathrm{BL} / 6$ genetic background by $\mathrm{Ng}$ et $a l^{26}$ and the homozygous mutant mice as well as their wild-type littermates were used in this study. Adult (8-12 weeks of age) male and female mice were housed five per cage under pathogenfree conditions, and were maintained in an environment with controlled temperature and humidity and a 12-h light/dark cycle. All animals were fed standard mouse chow and water ad libitum. Naphthalene (>99\% pure; Sigma Chemical, St Louis, MO, USA) was dissolved in corn oil (Sigma Chemical) and administered at a dose of $200 \mathrm{mg} / \mathrm{kg}$ body weight. Naphthalene or corn oil alone $(10 \mathrm{ml} / \mathrm{kg}$ body weight, 
vehicle control) was administered by a single intraperitoneal injection. The dose of naphthalene used in this study was chosen based on our previous dose-response studies, which showed that the $200 \mathrm{mg} / \mathrm{kg}$ dose is sufficient to specifically ablate Clara cells with a subsequently adequate repair response in both male and female mice. ${ }^{34}$ Groups of 3-5 mice were killed at different time points $(0,1,2,5,14$, and 21 days) after treatment with naphthalene or at 2 days after corn oil treatment (control group). In order to minimize the influence of diurnal fluctuations in glutathione abundance on the extent of naphthalene injury, all mice were dosed and killed in the morning between 0800 and 1000 hours. All the animal studies were reviewed and approved by The Hospital for Sick Children institutional animal care committee for humane use of laboratory animals.

\section{Histopathological Analysis}

Immediately after death, mouse lung tissue was collected for routine histology and was fixed overnight in $10 \%$ buffered formalin followed by paraffin embedding. Each mouse was processed so that each paraffin-embedded tissue block contained all of the lobes of the lungs. Lung tissue sections $(5 \mu \mathrm{m})$ were stained with hematoxylin and eosin (H\&E) for histological examination under a light microscope. H\&Estained mouse lung sections were scored for extent of naphthalene-induced bronchiolar epithelial (Clara) cell necrosis as previously described by Oliver et al. ${ }^{34}$ The degree of necrosis was estimated semiquantitatively, and was expressed for each mouse as the mean of 10 random fields ( 1 to 2 airways per field) at $\times 400$ magnification within each section (one section per mouse) classified on a scale of $0-3$. Scoring criteria were as follows: 0 , no necrosis, defined as no detection of necrotic bronchiolar epithelial cells exfoliated within the airway lumen; 1 , mild, defined as only occasional detection of necrotic bronchiolar epithelial cells exfoliated within the airway lumen; 2, moderate, defined as more frequent detection of necrotic bronchiolar epithelial cells exfoliated within the airway lumen; 3 , severe, defined as very frequent detection of numerous necrotic bronchiolar epithelial cells within the airway lumen. Data are presented as the mean necrosis score \pm s.e.m. of 3-5 mice per group at each time point after naphthalene treatment.

\section{Immunofluorescence/Immunohistochemical Labeling Analysis}

Serial sections of formalin-fixed and paraffin-embedded mouse lung tissue were also used for immunohistochemical staining for the following: (1) the Clara cell marker CC10/ CCSP; (2) the ciliated cell marker $\beta$-Tubulin IV; $(3)$ the pulmonary neuroendocrine cell (PNEC)/neuroepithelial body (NEB) markers synaptophysin (SYN) and calcitonin gene-related peptide (CGRP); (4) the cell proliferation marker Ki-67; (5) the mitosis marker phosphohistone-3 (PH-3); and (6) TGF- $\beta$ RII.
For immunofluorescent staining, sections $(5 \mu \mathrm{m})$ were deparaffinized, rehydrated, and then microwaved in $0.01 \mathrm{M}$ citrate buffer $(\mathrm{pH} 6.0)$ for $18.5 \mathrm{~min}$ at $1000 \mathrm{~W}$ for antigen unmasking. Sections were kept in the hot citrate buffer solution for an additional $20 \mathrm{~min}$, washed in water, and then transferred to phosphate-buffered saline ( $\mathrm{pH}$ 7.2). Tissue sections were blocked with $10 \%$ normal donkey serum for $1 \mathrm{~h}$ at room temperature, and then incubated with the following primary antibodies: goat polyclonal anti-mouse CC10/CCSP (Santa Cruz Biotechnology, Santa Cruz, CA, USA) in a 1:1000 dilution; mouse monoclonal anti- $\beta$ Tubulin IV (Sigma) in a 1:100 dilution; rabbit monoclonal anti-human Ki-67 (Lab Vision Corporation, Fremont, CA, USA) in a 1:100 dilution; and rabbit polyclonal anti-human TGF- $\beta$ RII (Santa Cruz Biotechnology) in a 1:200 dilution. All primary antibodies were incubated on tissue sections for $2 \mathrm{~h}$ at room temperature, and the optimal antibody concentration that gave positive tissue staining with minimal background staining was determined separately for each antibody using a series of dilutions. CC10/CCSP was detected with a donkey anti-goat IgG secondary antibody conjugated to an Alexa 488 fluorophore (Invitrogen, Burlington, ON, Canada). $\beta$-Tubulin IV was detected with a donkey antimouse IgG secondary antibody conjugated to an Alexa 647 fluorophore (Invitrogen). In order to reduce nonspecific binding of the anti-mouse secondary antibody to endogenous mouse IgG antibodies, a Mouse-on-Mouse blocking step was employed before the serum blocking step by incubating tissue sections with $\mathrm{F}\left(\mathrm{ab}^{\prime}\right)_{2}$ fragment donkey antimouse IgG $(\mathrm{H}+\mathrm{L})$ (Jackson ImmunoResearch Laboratories, West Grove, PA, USA) in a 1:50 dilution for $1 \mathrm{~h}$ at room temperature followed by overnight incubation at $4{ }^{\circ} \mathrm{C}$ and then washing extensively. Ki-67 was detected with a donkey anti-rabbit IgG secondary antibody conjugated to an Alexa 555 fluorophore (Invitrogen). TGF- $\beta$ RII was detected with a donkey anti-rabbit IgG secondary antibody conjugated to an Alexa 488 fluorophore (Invitrogen). All secondary antibodies were incubated on tissue sections in a 1:500 dilution for $1 \mathrm{~h}$ at room temperature. Tissue sections were counterstained with DAPI, and sections stained without primary antibody served as negative controls. Immunofluorescent images were captured at $\times 300$ magnification on a Quorum spinning disk confocal microscope (Leica DMIRE2 inverted fluorescence microscope) equipped with a Hamamatsu back-thinned EM-CCD camera and Yokogawa scan head. The unit is also equipped with four separate diode-pumped solid-state laser lines (Spectral Applied Research: $405 \mathrm{~nm}, 491 \mathrm{~nm}, 561 \mathrm{~nm}, 638 \mathrm{~nm}$ ), an ASI motorized XY stage, an Improvision Piezo Focus Drive, and a $\times 1.5$ magnification lens coupler. The equipment is driven by Improvision Volocity acquisition software, and powered by an Apple Power Mac G5. Acquisition settings were optimized to obtain maximal signal in immunostained sections with minimal background in negative control sections. 
For colorimetric immunohistochemical staining, everything was initially done exactly as already described for immunofluorescent staining; however, after antigen unmasking, sections were also treated with $3 \%$ hydrogen peroxide in methanol for $15 \mathrm{~min}$ in order to quench endogenous peroxidase activity. Tissue sections were blocked with $10 \%$ normal goat serum for $1 \mathrm{~h}$ at room temperature, and then incubated with one of the following primary antibodies: rabbit monoclonal anti-human SYN (NeoMarkers, Fremont, CA, USA) in a 1:100 dilution; mouse monoclonal anti-human CGRP (Abcam, Cambridge, MA, USA) in a 1:150 dilution; rabbit monoclonal anti-human Ki-67 (Lab Vision Corporation) in a 1:200 dilution; or rabbit polyclonal anti-human PH-3 (Upstate Laboratories, Temecula, CA, USA) in a 1:6000 dilution. Primary antibodies were incubated overnight on tissue sections at $4{ }^{\circ} \mathrm{C}$ and immunohistochemical staining was carried out using the immunoperoxidase method according to the guidelines for the Vectastain Elite $A B C$ Peroxidase Kit (Vector Laboratories, Burlingame, CA, USA). Sites of peroxidase binding were detected with the chromogenic 3,3'-diaminobenzidine tetrahydrochloride (DAB) substrate, and positive staining appeared brown in color. Tissue sections were counterstained with hematoxylin, and sections stained without primary antibody served as negative controls.

\section{Quantification of Immunoreactivity Against CC10/CCSP and TGF- $\beta$ RII}

Using Improvision Volocity image analysis software, the fluorescent intensity of immunopositive signal for both CC10/CCSP and TGF- $\beta$ RII was individually measured in the distal bronchiolar airway epithelium on unprocessed raw data images captured at $\times 300$ magnification. More specifically, it was the mean fluorescent intensity of immunopositive signal that was measured, which is the average intensity of all the pixels within the area (ie, bronchiolar epithelium) analyzed in an image. Distal bronchiolar airways were defined as distal conducting airways with a diameter of $\leq 250 \mu \mathrm{m}$, and the bronchiolar airway epithelium was defined as the cells located between the basal lamina and the airway lumen. It should be noted that the intensity of immunoreactivity was measured only within the intact and undamaged bronchiolar epithelium and that injured and necrotic epithelial cells, which had detached from the basal lamina and exfoliated into the airway lumen, were not included in the analysis. This analysis was performed in a similar manner to that previously described by Chen et al $l^{35}$ with few modifications. As every microscope slide contained two serial sections of the same mouse lung tissue sample (ie, one section was used for immunostaining and the other section was used as a negative control), the fluorescent intensity of both immunopositive signal and autofluorescence could be measured in the exact same airways analyzed. Because the degree of background autofluorescence can vary in different sections, the data were normalized as a ratio by dividing the fluorescent intensity value obtained for immunopositive signal by the fluorescent intensity value obtained for autofluorescence. The normalized values were then averaged from all of the airways analyzed in images taken from five random fields ( 1 to 2 airways per field) per section (one section per mouse) to produce a mean airway fluorescent intensity value for each mouse sample. The values for each mouse in every group were then averaged, and the data are presented as means \pm s.e.m. of 3-5 mice per group at each time point after treatment with naphthalene.

\section{Measurement of Ki-67 Labeling Index and PH-3 Mitotic Index}

As previously described by Oliver et al, ${ }^{34}$ the labeling index (LI) was determined with the cell proliferation marker Ki-67, and was expressed as the percentage of $\mathrm{Ki}-67$-positive nuclei in the distal bronchiolar airway epithelium and in the peribronchiolar interstitium. The peribronchiolar interstitium was defined as the cells located between the basal lamina of the distal bronchiolar airway epithelium and an adjacent blood vessel, alveolus, or bronchiole. The number of Ki-67positive nuclei and the total number of nuclei in the distal bronchiolar airway epithelium and in the peribronchiolar interstitium were counted separately in five random fields ( 1 to 2 airways per field) per section under a light microscope at $\times 400$ magnification. The LI was calculated by dividing the number of Ki-67-positive nuclei by the total number of nuclei per section (one section per mouse). Data are presented as means \pm s.e.m. of 3-5 mice per group at each time point after treatment with naphthalene. In order to confirm the differences in lung repair kinetics initially observed with the Ki-67 LI data, the mitotic index (MI) was also determined exactly as described above for the LI; however, instead of $\mathrm{Ki}-67$, the mitosis marker $\mathrm{PH}-3$ was detected.

\section{Western Blotting Analysis}

Equal amounts of protein derived from mouse lung tissue homogenates were loaded onto a 15\% SDS-polyacrylamide gel, separated by electrophoresis, and transferred onto a nitrocellulose membrane (Bio-Rad Laboratories, Hercules, CA, USA). The blot was next blocked in TBST with $5 \%$ non-fat milk and $2 \%$ FBS, and then incubated with rabbit polyclonal anti-mouse CC10/CCSP antibody (Santa Cruz Biotechnology) in a 1:500 dilution overnight at $4{ }^{\circ} \mathrm{C}$. After washing thoroughly in TBST, the blot was then incubated with horseradish peroxidase-conjugated donkey anti-rabbit IgG secondary antibody (Amersham Pharmacia Biotech, Piscataway, NJ, USA). Detection of protein was performed with ECL chemiluminescence reagents (Amersham Pharmacia Biotech).

\section{Statistical Analysis}

The results of the experiments are expressed as the means \pm s.e.m. A one-way analysis of variance was used to evaluate the data followed by Tukey's post hoc tests for statistical 
comparisons between groups at different time points using Prism 4.0 software. Differences were considered to be statistically significant when $P<0.05$.

\section{RESULTS}

As it has been well established that there are sex differences in naphthalene metabolism and naphthalene-induced lung injury $^{36}$ as well as subsequent repair, ${ }^{34}$ we utilized both male and female mice in this study. Therefore, all data reported herein will first compare lung injury/repair responses between male wildtype (Elf3 $+I+)$ mice and male Elf3-deficient (Elf3- $/-$ ) mice (Figures 1-7) and then between female Elf3 $+/+$ mice and female Elf3-/- mice (Supplementary Figures S1-S7).

\section{Absence of Elf3 Does Not Affect the Severity of Naphthalene-Induced Bronchiolar Epithelial Injury in Elf3-Deficient Mice}

Naphthalene-induced histopathological changes were assessed by analysis of H\&E-stained lung sections, and the findings from male (Elf3 $+/+$ and Elf3 $-/-$ ) mice (Figure 1) are described here first. At day 0 of naphthalene treatment, no histopathological changes were detected and a normal bronchiolar airway epithelium was observed in the lungs of both Elf3 $+/+$ mice (Figure 1a) and Elf3 $-/-$ mice (Figure $1 \mathrm{~g}$ ) as expected for uninjured control groups. Similarly, a normal bronchiolar epithelium with no histopathological changes was also observed in both Elf3 $+/+$ and Elf3-/- mice upon treatment with corn oil (data not shown). An exfoliation of numerous injured and necrotic bronchiolar epithelial cells into the airway lumen was detected in both Elf3 $+/+$ mice (Figure 1b) and Elf3-Imice (Figure $1 \mathrm{~h}$ ) by day 1 post naphthalene injection. This sloughing of necrotic cells from the bronchiolar epithelium left the basement membrane denuded with some uninjured and flattened epithelial cells remaining intact. The excessive bronchiolar epithelial cell injury and exfoliation persisted at day 2 post naphthalene injection, and began to clear up by day 5 with just few residual necrotic bronchiolar epithelial cells detected within the airway lumen, in both Elf3 $+/+$ mice (Figure $1 \mathrm{c}$ and $\mathrm{d}$ ) and Elf3-l- mice (Figure $1 \mathrm{i}$ and $\mathrm{j}$ ).
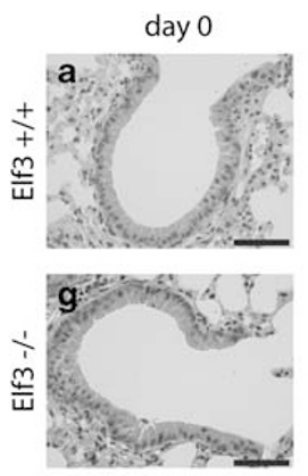

day 1
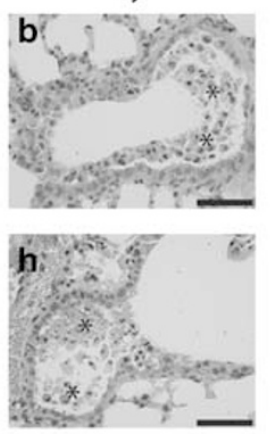

day 2
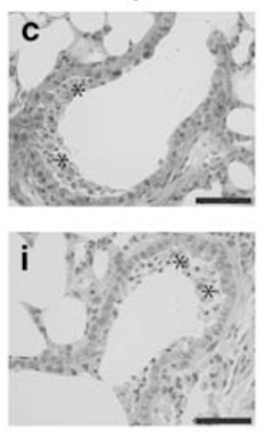

day 5
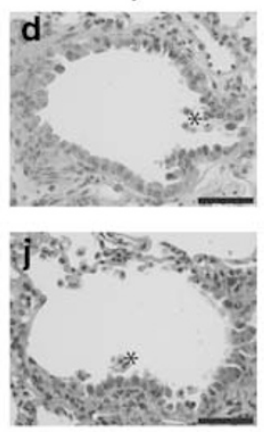

\section{day 14}
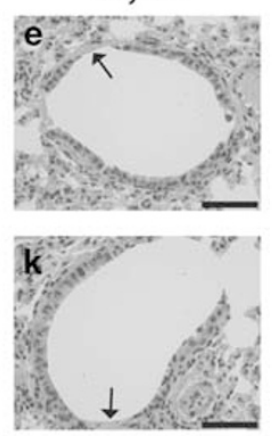
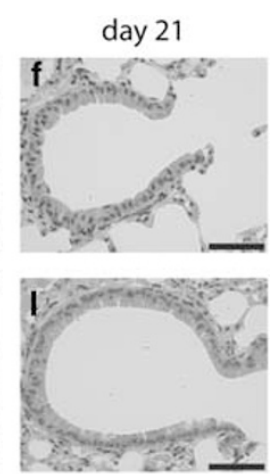

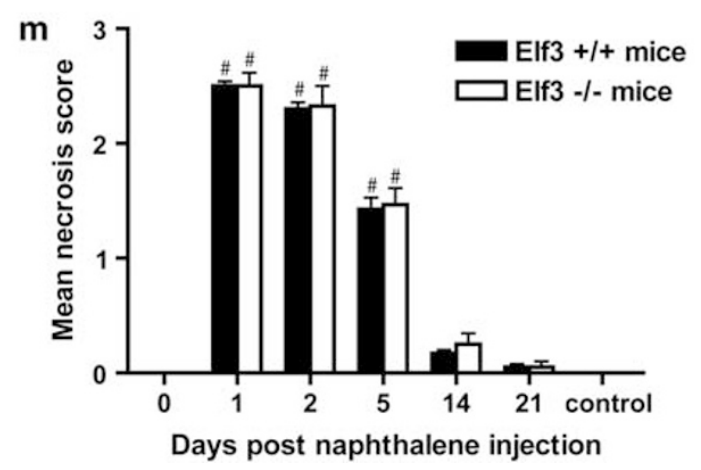

Figure 1 Histopathological analysis of H\&E-stained lung sections from male Elf3 $+/+(\mathbf{a}-\mathbf{f})$ and Elf3-/- (g-I) mice at $0(\mathbf{a}, \mathbf{g}), 1(\mathbf{b}, \mathbf{h}), 2(\mathbf{c}, \mathbf{i}), 5(\mathbf{d}, \mathbf{j}), 14$ $(\mathbf{e}, \mathbf{k})$, and 21 (f, l) days post naphthalene injection. A normal uninjured bronchiolar airway epithelium was detected in both Elf $3+/+(\mathbf{a})$ and Elf3-/- (g) mice at day 0 . Injured and necrotic bronchiolar epithelial cells, which had exfoliated into the airway lumen, were detected in both Elf $3+/+($ asterisks in b-d) and Elf3-/- (asterisks in $\mathbf{h}-\mathbf{j}$ ) mice at 1-5 days post naphthalene injection. Bronchiolar airways had recovered from the naphthalene injury by $14-21$ days in both Elf $3+/+(\mathbf{e}, \mathbf{f})$ and Elf3 $-/-(\mathbf{k}, \mathbf{l})$ mice; however, some visible areas of denuded basement membrane were observed in both Elf3 $+/+$ (arrow in e) and Elf3-/- (arrow in k) mice at day 14. Photomicrographs are representative of 3-5 mice per group at each time point after treatment with naphthalene (original magnification $\times 400)$. Scale bar $(\mathbf{a}-\mathrm{I}), 50 \mu \mathrm{m}$. The extent of naphthalene-induced bronchiolar epithelial cell necrosis was estimated semiquantitatively in both Elf $3+/+$ and Elf $3-/-$ mice, and is expressed as the mean necrosis score (m). The degree of necrosis was expressed for each mouse as the mean of 10 random fields within each section (one section per mouse) classified on a scoring scale of $0-3$. See Materials and methods section for a detailed description of necrosis scoring criteria. Data are presented as the mean necrosis score \pm s.e.m. of 3-5 mice per group at each time point after naphthalene treatment or at 2 days after treatment with corn oil (control). "Significantly different from both the day 0 and corn oil (control) groups $(P<0.05)$. 
By day 14 post naphthalene treatment, the bronchiolar airway epithelium appeared to be almost completely restored with just some visible areas of denuded basement membrane remaining, and by day 21 , regeneration of the airway epithelium was observed to be complete, in both Elf3 $+/+$ mice (Figure 1e and f) and Elf3- $/-$ mice (Figure $1 \mathrm{k}$ and 1 ).

The extent of naphthalene-induced bronchiolar epithelial cell necrosis was measured semiquantitatively by scoring the H\&E-stained lung sections. For the day 0 and corn oil (control) groups of both Elf3 $+/+$ and Elf3- $/-$ mice, the mean necrosis score was at a low baseline level of 0 (Figure $1 \mathrm{~m}$ ) as expected for uninjured animals. The mean necrosis score was significantly greater than control levels and at a maximum at 1 to 2 days post naphthalene injection, and began to decrease thereafter, returning to near baseline control levels by 14-21 days in both Elf3 $+/+$ and Elf3-Imice (Figure $1 \mathrm{~m}$ ). The mean necrosis score was not significantly different at any time point when comparing Elf3 $+I+$ and Elf3 $-I-$ mice (Figure $1 \mathrm{~m}$ ), indicating that naphthalene-induced bronchiolar epithelial injury occurs to the same extent in both Elf3 $+/+$ and Elf3 $-I-$ mice.

The naphthalene-induced histopathological changes observed in the lungs of female (Elf3 $+/+$ and Elf3-I-) mice were consistent with that observed in male $($ Elf3 $+/+$ and Elf3-/-) mice, as described above, with the exception that the bronchiolar epithelial injury and necrosis was more severe in the female mice (Supplementary Figure S1). Therefore, the mean necrosis score values were higher in
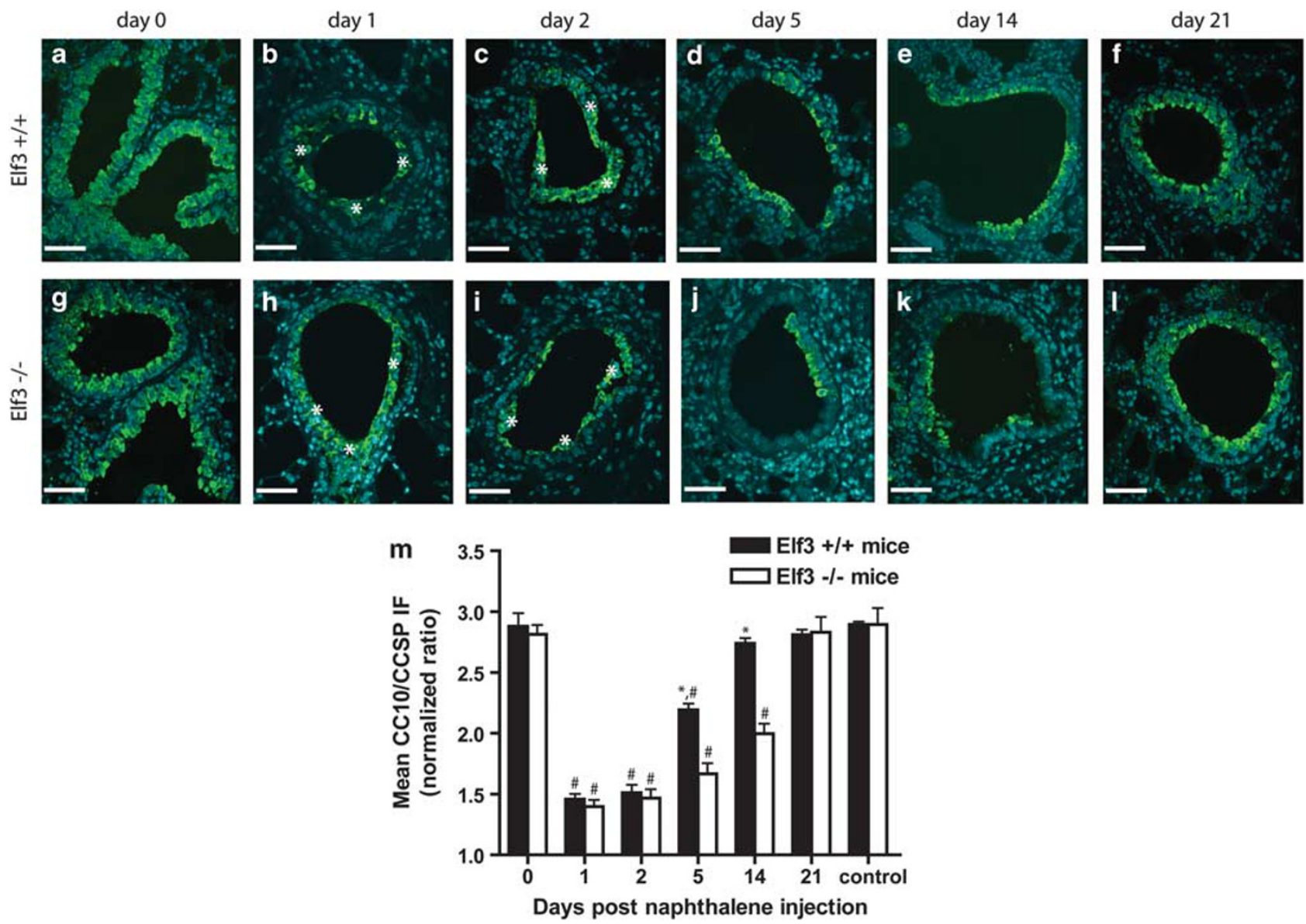

Figure 2 Immunofluorescent staining for the Clara cell marker CC10/CCSP (green) in male Elf3 $+/+(\mathbf{a}-\mathbf{f})$ and Elf3-/- (g-l) mouse lung at 0 (a, $\mathbf{g}), 1$ (b, h), $2(\mathbf{c}, \mathbf{i}), 5(\mathbf{d}, \mathbf{j}), 14(\mathbf{e}, \mathbf{k})$, and 21 (f, I) days post naphthalene injection. Sections were counterstained with DAPI (blue) for detection of all cells. At day 0 , a normal uninjured bronchiolar airway epithelium, which stained strongly for CC10/CCSP, was detected in both Elf3 $+/+$ (a) and Elf3-/- (g) mice. By 1 to 2 days post naphthalene injection, an exfoliation of injured and necrotic Clara cells into the airway lumen was observed in both Elf3 $+/+($ asterisks in $\mathbf{b}, \mathbf{c})$ and Elf3-/- (asterisks in h, i) mice. Clara cell regeneration was almost completely restored by day 14 in Elf $3+/+$ mice (e); however, regeneration was substantially delayed in Elf3-/- mice and did not reach completion until day 21 ( I). Photomicrographs are representative of 3-5 mice per group at each time point after naphthalene treatment (original magnification $\times 300$ ). Scale bar $(\mathbf{a}-\mathbf{l}), 50 \mu \mathrm{m}$. The fluorescent intensity of CC10/CCSP immunoreactivity was measured within the intact and undamaged bronchiolar airway epithelium of both Elf3 $+/+$ and Elf $3-/-$ mice, and is expressed as a normalized ratio of immunopositive signal to autofluorescence $(\mathbf{m})$. See Materials and methods section for a more detailed description of how this analysis was performed. Data are presented as the mean CC10/CCSP immunofluorescence (IF) \pm s.e.m. of 3-5 mice per group at each time point after treatment with naphthalene or at 2 days after treatment with corn oil (control). ${ }^{*}$ Significantly different from that of Elf3-/- mice at same time point after naphthalene treatment $(P<0.05)$. "Significantly different from both the day 0 and corn oil (control) groups $(P<0.05)$. 
female (Elf3 $+I+$ and Elf3-I-) mice (Supplementary Figure $\mathrm{S} 1 \mathrm{~m}$ ) than in the male (Elf3 $+/+$ and Elf3-I-) mice (Figure $1 \mathrm{~m}$ ) at all time points after injection with naphthalene. Most importantly, the overall trend observed in the male mice, in which the naphthalene-induced bronchiolar epithelial injury occurs to the same extent in both Elf3 $+/+$ and Elf3 $-1-$ mice, was conserved among female mice as the mean necrosis score was not significantly different at any
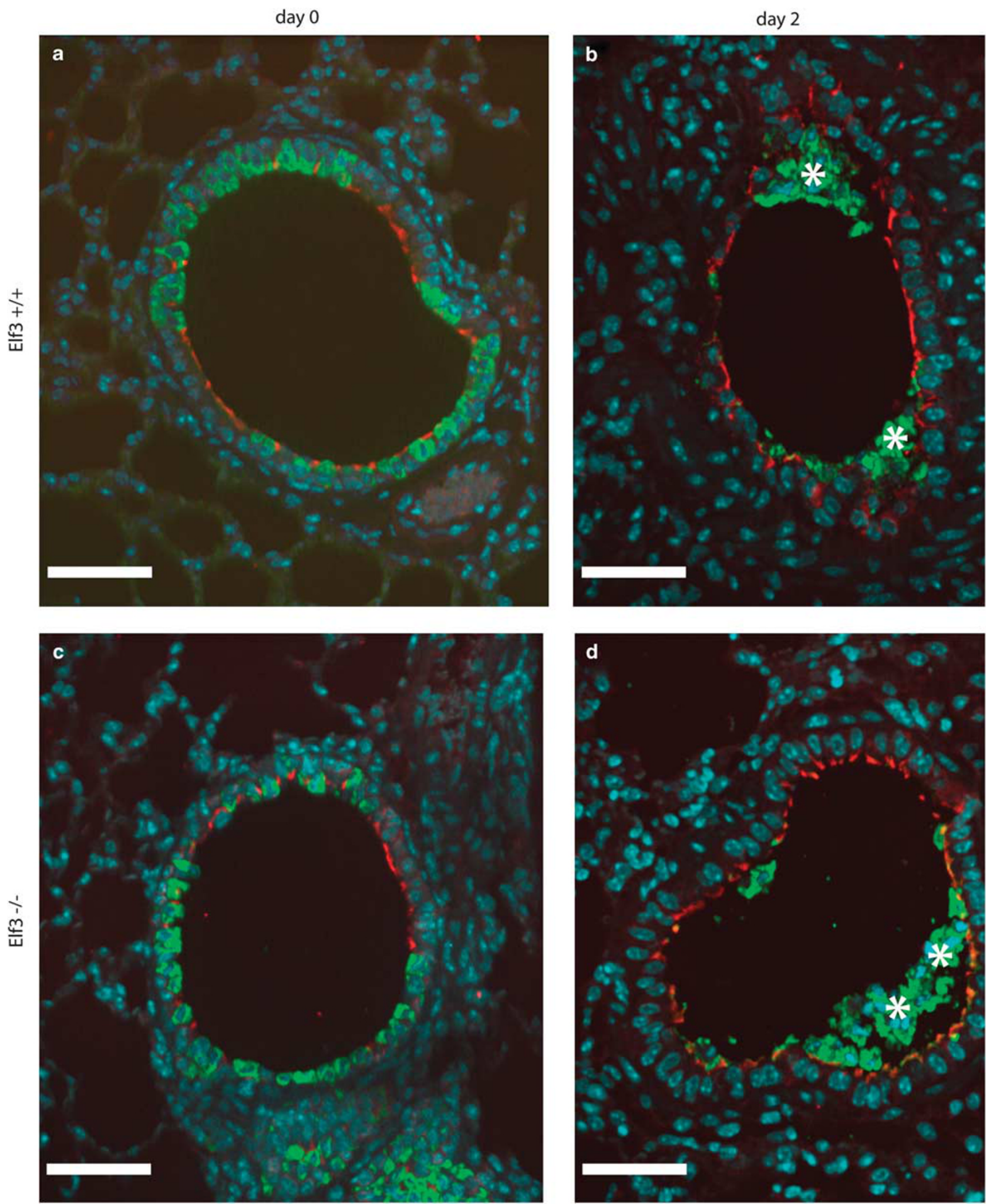
time point when comparing Elf3 $+/+$ and Elf3 $-/-$ mice (Supplementary Figure S1m).

\section{Delayed Clara Cell Renewal Kinetics within the Bronchiolar Airway Epithelium of Elf3-Deficient Mice Following Naphthalene-Induced Clara Cell Depletion}

In order to follow the fate of Clara cells during naphthaleneinduced bronchiolar epithelial injury and repair, immunofluorescent staining for the Clara cell marker CC10/CCSP was performed, and the data from male (Elf3 $+1+$ and Elf3-/-) mice (Figure 2) are presented here first. At day 0, strong expression of CC10/CCSP was detected within the bronchiolar airway epithelium of both $\mathrm{Elf} 3+/+$ mice
(Figure 2a) and Elf3-/- mice (Figure 2g) as expected for uninjured control groups. Similarly, strong expression of CC10/CCSP was also observed within the airway epithelium of both Elf3 $+1+$ and Elf3 $-I-$ mice upon treatment with corn oil (data not shown). Injured and necrotic bronchiolar epithelial cells, which had exfoliated into the airway lumen, stained positively for CC10/CCSP in both Elf3 $+/+$ mice (Figure $2 \mathrm{~b}$ and $\mathrm{c}$ ) and Elf3-/- mice (Figure $2 \mathrm{~h}$ and $\mathrm{i}$ ) at 1 to 2 days after naphthalene injection, confirming that the naphthalene-induced airway epithelial injury was specific to Clara cells. In addition, signal for CC10/CCSP was substantially diminished within the residual intact bronchiolar airway epithelium of both Elf3 $+/+$ mice (Figure $2 \mathrm{~b}$ and $\mathrm{c}$ )
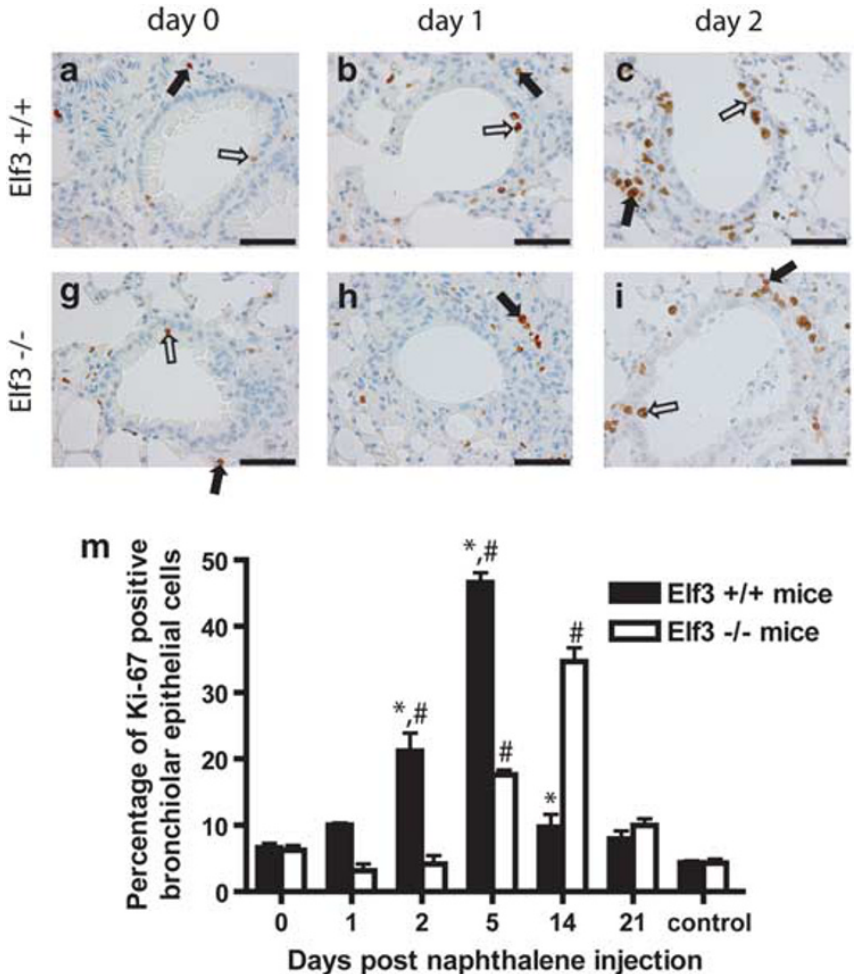

day 5
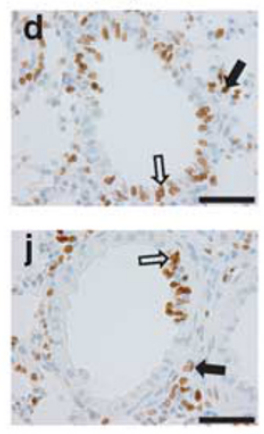

day 14
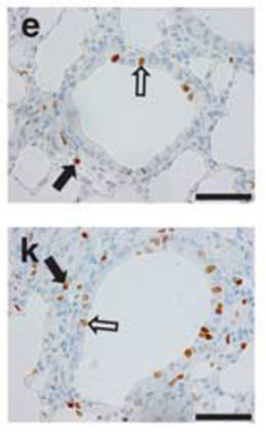
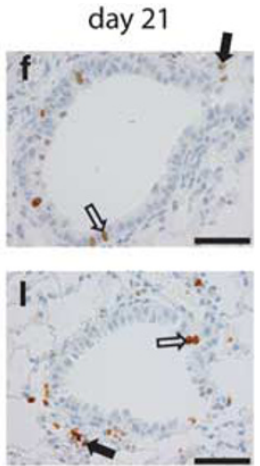

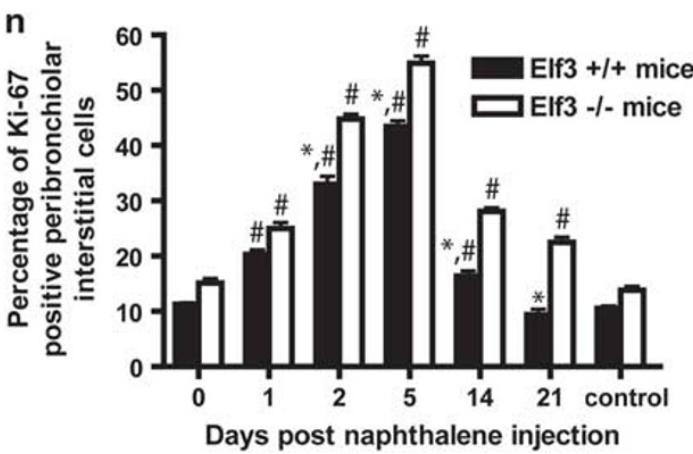

Figure 4 Immunohistochemical staining for the cell proliferation marker Ki-67 in male Elf3 $+/+(\mathbf{a}-\mathbf{f})$ and Elf3-/- (g-I) mouse lung at 0 (a, $\mathbf{g}), 1(\mathbf{b}$, $\mathbf{h})$, $2(\mathbf{c}, \mathbf{i}), 5(\mathbf{d}, \mathbf{j}), 14(\mathbf{e}, \mathbf{k})$, and $21(\mathbf{f}, \mathbf{I})$ days post naphthalene injection. Ki-67-positive nuclei are brown in color, and were detected in both the distal bronchiolar airway epithelium (open arrows) and peribronchiolar interstitium (closed arrows). Sections were counterstained with hematoxylin for detection of all nuclei, and photomicrographs are representative of 3-5 mice per group at each time point after naphthalene treatment (original magnification $\times 400$ ). Scale bar $(\mathbf{a}-\mathbf{l}), 50 \mu \mathrm{m}$. The percentage of Ki-67-positive cells was quantified in both the distal bronchiolar airway epithelium (m) and peribronchiolar interstitium (n), and results are presented as means \pm s.e.m. of 3-5 mice per group at each time point after treatment with naphthalene or at 2 days after treatment with corn oil (control). ${ }^{*}$ Significantly different from that of Elf3-/- mice at same time point after naphthalene treatment $(P<0.05)$. "Significantly different from both the day 0 and corn oil (control) groups $(P<0.05)$.

Figure 3 Double immunofluorescent staining for the Clara cell marker CC10/CCSP (green) and the ciliated cell marker $\beta$-Tubulin IV (red) in male Elf3 $+/+$ $(\mathbf{a}, \mathbf{b})$ and Elf3-/ $-(\mathbf{c}, \mathbf{d})$ mouse lung at $0(\mathbf{a}, \mathbf{c})$ and $2(\mathbf{b}, \mathbf{d})$ days post naphthalene injection. Sections were counterstained with DAPI (blue) for detection of all cells. At day 0 , a normal uninjured bronchiolar airway epithelium, containing many CC10/CCSP-positive (Clara) and $\beta$-Tubulin IV-positive (ciliated) cells, was detected in both Elf3 $+/+(\mathbf{a})$ and Elf3-/- (c) mice. At day 2, numerous injured and necrotic Clara cells, which had detached from the basement membrane and exfoliated into the airway lumen, were detected in both Elf3 $+/+$ (asterisks in b) and Elf3-/- (asterisks in d) mice, whereas ciliated cells were observed as intact and undamaged cells covering the denuded basement membrane of the injured airway epithelium in both Elf $3+/+$ (b) and Elf3 $-/-$ (d) mice. Photomicrographs are representative of 3-5 mice per group at each time point after naphthalene treatment (original magnification $\times 300)$. Scale bar $(\mathbf{a}-\mathbf{d}), 50 \mu \mathrm{m}$. 

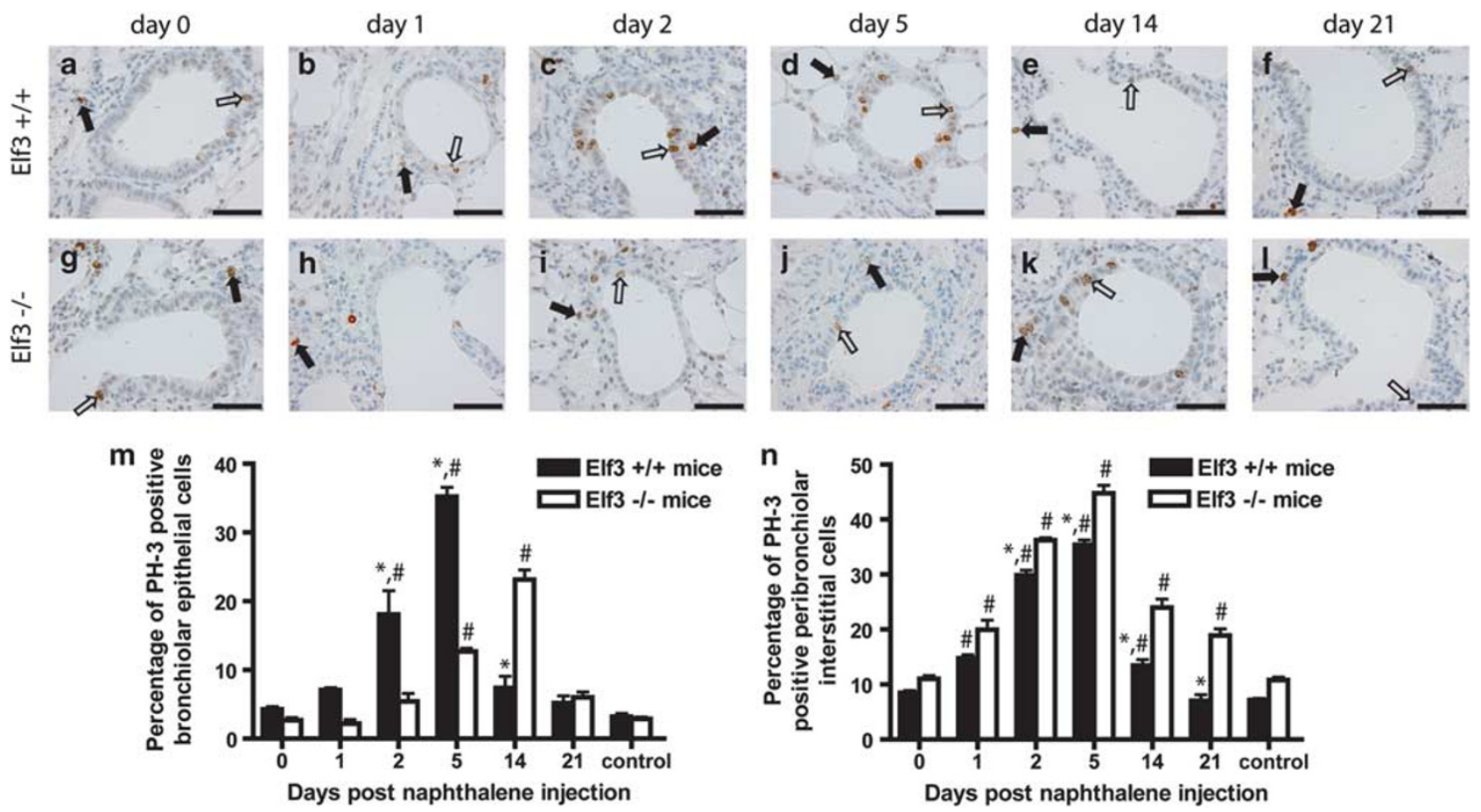

Figure 5 Immunohistochemical staining for the mitosis marker PH-3 in male Elf3 $+/+(\mathbf{a}-\mathbf{f})$ and Elf3-/- (g-I) mouse lung at $0(\mathbf{a}, \mathbf{g}), 1(\mathbf{b}, \mathbf{h}), 2(\mathbf{c}, \mathbf{i}), 5(\mathbf{d}, \mathbf{j})$, $14(\mathbf{e}, \mathbf{k})$, and 21 (f, I) days post naphthalene injection. $\mathrm{PH}-3$-positive nuclei are brown in color, and were detected in both the distal bronchiolar airway epithelium (open arrows) and peribronchiolar interstitium (closed arrows). Sections were counterstained with hematoxylin for detection of all nuclei, and photomicrographs are representative of 3-5 mice per group at each time point after naphthalene treatment (original magnification $\times 400$ ). Scale bar (a-l), $50 \mu \mathrm{m}$. The percentage of PH-3-positive cells was quantified in both the distal bronchiolar airway epithelium (m) and peribronchiolar interstitium (n), and results are presented as means \pm s.e.m. of 3-5 mice per group at each time point after treatment with naphthalene or at 2 days after treatment with corn oil (control). "Significantly different from that of Elf3-/- mice at same time point after naphthalene treatment $(P<0.05)$. ${ }^{\#}$ Significantly different from both the day 0 and corn oil (control) groups $(P<0.05)$.

and Elf3- $/-$ mice (Figure $2 \mathrm{~h}$ and $\mathrm{i}$ ) at 1 to 2 days post naphthalene injection. By 5-14 days post naphthalene treatment, signal for CC10/CCSP began to increase within the airway epithelium of Elf3 $+/+$ mice (Figure $2 \mathrm{~d}$ and e) to a greater extent than within that of Elf3-I- mice (Figure $2 j$ and $\mathrm{k}$ ), suggesting delayed Clara cell renewal in Elf3-/mice. However, by day 21, CC10/CCSP signal within the airway epithelium of both Elf3 $+/+$ mice (Figure $2 \mathrm{f}$ ) and Elf3-/ - mice (Figure 2l) was similar to that observed in uninjured day 0 control mice (Figure $2 \mathrm{a}$ and $\mathrm{g}$ ), indicating completion of Clara cell reconstitution in both Elf3 $+/+$ and Elf3-/- mice.

In order to quantify the amount of CC10/CCSP immunoreactivity, the fluorescent intensity of immunopositive signal was measured within the intact and undamaged bronchiolar airway epithelium and was expressed as the mean CC10/CCSP immunofluorescence (IF) normalized to autofluorescence, as described in the Materials and methods. By 1 to 2 days after naphthalene injection, the mean CC10/ CCSP IF in both Elf3 $+/+$ and Elf3- $/-$ mice had decreased significantly below that in their respective day 0 and corn oil (control) groups (Figure $2 \mathrm{~m}$ ). Moreover, the mean CC10/ CCSP IF was not significantly different between Elf3 $+/+$ and Elf3-I- mice at 1 to 2 days post naphthalene injection
(Figure $2 \mathrm{~m}$ ), further indicating that there is no considerable difference in the extent of naphthalene-induced Clara cell depletion when comparing Elf3 $+/+$ and Elf3 $-/-$ mice. At 5-14 days post naphthalene injection, the mean CC10/ CCSP IF increased at a faster rate and was significantly greater in Elf3 $+/+$ mice than in Elf3- $/$ - mice (Figure $2 \mathrm{~m}$ ), suggesting a considerable delay in the kinetics of Clara cell renewal within the bronchiolar airway epithelium of Elf3-/mice. Western blot analysis of CC10/CCSP expression in lung homogenates at day 14 post naphthalene treatment showed a similar trend with more expression in Elf3 $+1+$ mice than in Elf3-/- mice (data not shown). Furthermore, at day 14, the mean CC10/CCSP IF in Elf3-/- mice was still significantly lower than that in their respective day 0 and corn oil (control) groups, whereas Elf3 $+/+$ mice had already recovered as their mean CC10/CCSP IF was not significantly different than control levels (Figure $2 \mathrm{~m}$ ). However, by day 21 after treatment with naphthalene, Elf3-/mice eventually recovered as their mean CC10/CCSP IF had increased substantially and was no longer significantly different than control levels (Figure $2 \mathrm{~m}$ ).

The histological changes in Clara cells observed in female (Elf3 $+/+$ and Elf3-I-) mice (Supplementary Figure S2) were consistent with that observed in male (Elf3 $+/+$ and 

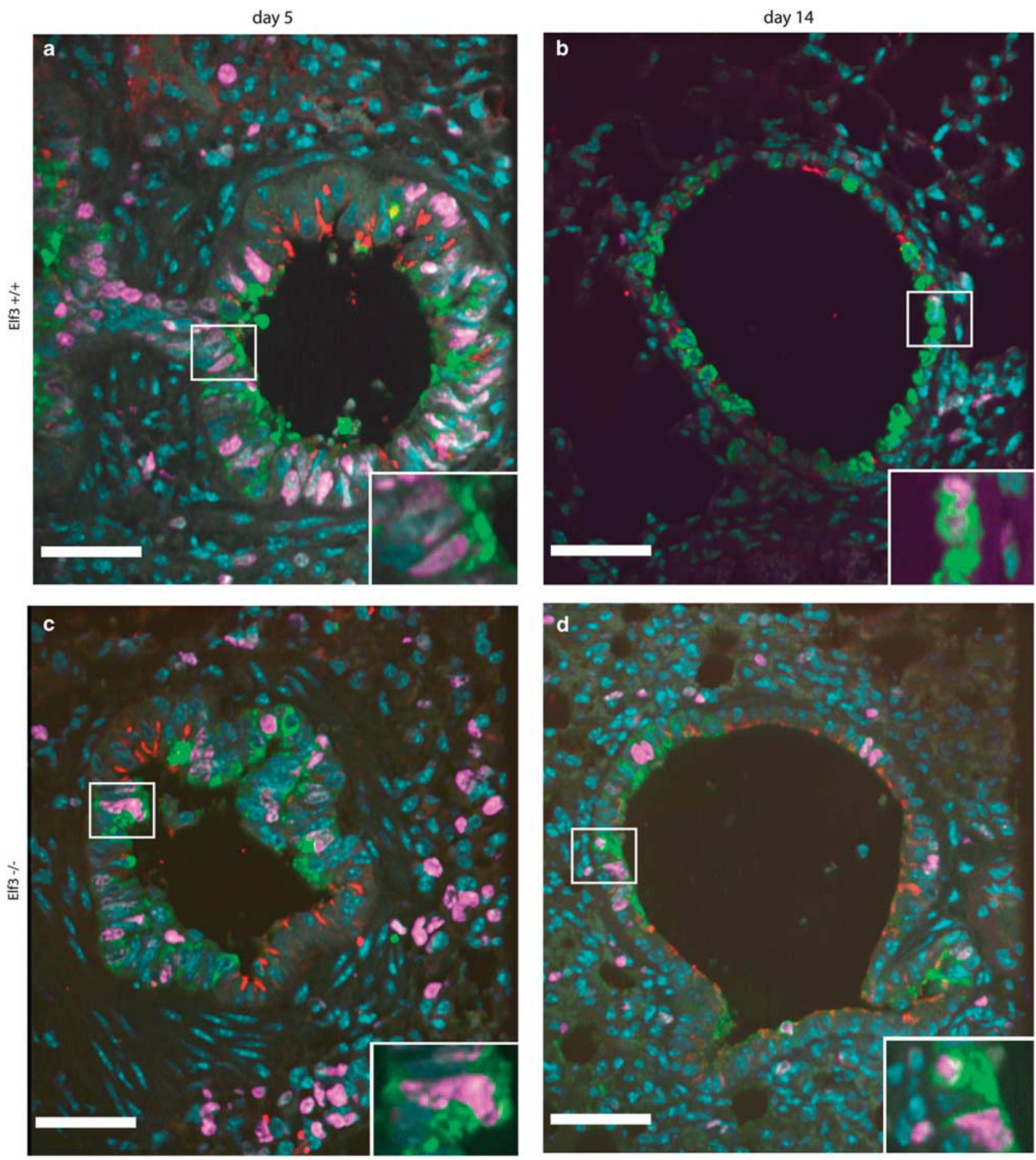

Figure 6 Triple immunofluorescent staining for the Clara cell marker CC10/CCSP (green), the ciliated cell marker $\beta$-Tubulin IV (red), and the cell proliferation marker Ki-67 (purple) in male Elf3 $+/+(\mathbf{a}, \mathbf{b})$ and Elf3 $-/-(\mathbf{c}, \mathbf{d})$ mouse lung at $5(\mathbf{a}, \mathbf{c})$ and $14(\mathbf{b}$, d) days post naphthalene injection. Sections were counterstained with DAPI (blue) for detection of all cells. Numerous cells dually positive for both CC10/CCSP and Ki-67 were detected within the regenerating bronchiolar airway epithelium of both Elf $3+/+$ and Elf3 $-/-$ mice (as shown in insets), whereas no cells dually positive for both $\beta$-Tubulin IV and $\mathrm{Ki}-67$ were detected in both Elf3 $+/+$ and Elf3-/- mice. Photomicrographs are representative of 3-5 mice per group at each time point after naphthalene treatment (original magnification $\times 300$ ). Scale bar $(\mathbf{a}-\mathbf{d}), 50 \mu \mathrm{m}$.

Elf3-/-) mice, as described above. However, as female mice are more susceptible to naphthalene toxicity, they have more extensive Clara cell injury and necrosis than male mice.
Therefore, the mean CC10/CCSP IF levels decreased to a greater degree in female (Elf3 $+/+$ and Elf3-/-) mice (Supplementary Figure S2m) than in the male (Elf3 $+/+$ 

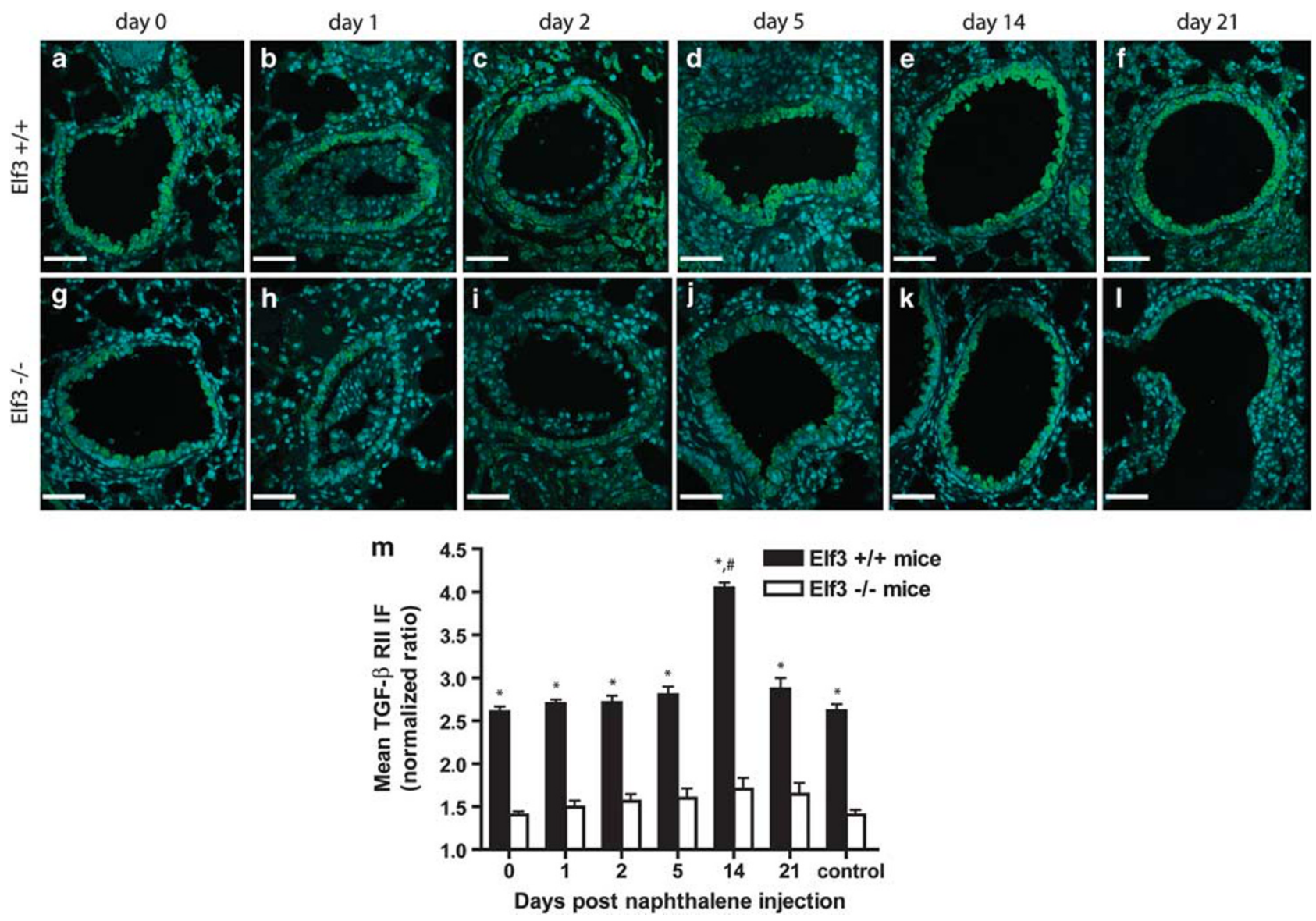

Figure 7 Immunofluorescent staining for TGF- $\beta$ RII (green) in male Elf3 $+/+(\mathbf{a}-\mathbf{f})$ and Elf3-/- (g-I) mouse lung at 0 (a, g), 1 (b, h), 2 (c, i), 5 (d, j), 14 (e, k), and 21 (f, I) days post naphthalene injection. Sections were counterstained with DAPI (blue) for detection of all cells. Immunopositive signal for TGF- $\beta$ RII detected within the bronchiolar airway epithelium of Elf3 $+/+$ mice was more intense than that of Elf3 $-/-$ mice. At day 14 , the intensity of immunopositive signal for TGF- $\beta$ RIl observed in Elf $3+/+$ mice increased substantially compared with that seen in the respective day 0 control mice, whereas in Elf3-/- mice, it did not change much compared with their respective control mice. Photomicrographs are representative of 3-5 mice per group at each time point after naphthalene treatment (original magnification $\times 300$ ). Scale bar (a-I), $50 \mu \mathrm{m}$. The fluorescent intensity of TGF- $\beta$ RII immunoreactivity was measured within the intact and undamaged bronchiolar airway epithelium of both Elf3 $+/+$ and Elf $3-/-$ mice, and is expressed as a normalized ratio of immunopositive signal to autofluorescence $(\mathbf{m})$. See Materials and methods section for a more detailed description of how this analysis was performed. Data are presented as the mean TGF- $\beta$ RII immunofluorescence (IF) \pm s.e.m. of 3-5 mice per group at each time point after treatment with naphthalene or at 2 days after treatment with corn oil (control). "Significantly different from that of Elf3-/- mice at same time point after naphthalene treatment $(P<0.05)$. "Significantly different from both the day 0 and corn oil (control) groups $(P<0.05)$.

and Elf3-/-) mice (Figure $2 \mathrm{~m}$ ) within 1 to 2 days after injection with naphthalene. Most importantly, the key finding made in the male mice, in which the kinetics of Clara cell renewal was delayed within the airway epithelium of Elf3-1- mice, was conserved among female mice as the mean CC10/CCSP IF increased at a faster rate and was significantly greater in Elf3 $+/+$ mice than in Elf3 $-/-$ mice at 5-14 days post naphthalene injection (Supplementary Figure S2m). However, just as observed in male Elf3-/mice, female Elf3-/ - mice eventually recovered by day 21 as their mean CC10/CCSP IF increased to a similar level as that detected within the airway epithelium of their respective day 0 and corn oil (control) groups (Supplementary Figure S2m).

\section{Ciliated Cells Remain Intact to Cover the Denuded Basement Membrane of the Injured Bronchiolar Airway Epithelium in Both Wild-Type and Elf3-Deficient Mice}

As the signal for CC10/CCSP had diminished substantially within the residual bronchiolar airway epithelium remaining intact in both Elf3 $+/+$ mice (Figure $2 \mathrm{~b}$ and c) and Elf3- mice (Figure $2 \mathrm{~h}$ and i) at 1 to 2 days after naphthalene exposure, we hypothesized that ciliated epithelial cells remained intact after the naphthalene-induced Clara cell ablation and could temporarily cover the denuded basement membrane of the injured bronchiolar epithelium until completion of Clara cell regeneration. In order to test this hypothesis, double immunofluorescent staining for both the Clara cell marker CC10/CCSP and the ciliated cell marker 
$\beta$-Tubulin IV was performed, and the results from male (Elf3 $+/+$ and Elf3-I-) mice (Figure 3 ) are described here first. In the uninjured day 0 control groups, a normal bronchiolar airway epithelium, consisting mainly of CC10/ CCSP-positive (Clara) cells and $\beta$-Tubulin IV-positive (ciliated) cells, was observed in both Elf3 $+/+$ mice (Figure $3 a$ ) and Elf3-/ - mice (Figure 3c) as expected. At day 2 post naphthalene injection, the injured and necrotic bronchiolar epithelial cells, which had exfoliated into the airway lumen, stained positively for CC10/CCSP but not for $\beta$-Tubulin IV in both Elf3 $+1+$ mice (Figure $3 \mathrm{~b}$ ) and Elf3- $/-$ mice (Figure 3d), further confirming that the bronchiolar epithelial injury was specific to Clara cells and that ciliated epithelial cells were not injured by the dose of naphthalene used in this study. More importantly, many of the residual and intact bronchiolar epithelial cells stained positively for $\beta$-Tubulin IV in both Elf3 $+/+$ mice (Figure $3 \mathrm{~b}$ ) and Elf3-/- mice (Figure 3d), suggesting that ciliated cells can remain behind to help cover up and possibly protect the denuded basement membrane of the injured bronchiolar airway epithelium following naphthalene-induced Clara cell ablation. All of the findings described above for male (Elf3 $+/+$ and Elf3- $/-$ ) mice were also consistent with the findings in female (Elf3 $+/+$ and Elf3-I-) mice (Supplementary Figure S3).

\section{Kinetics of Cell Proliferation and Mitosis Is Delayed Within the Bronchiolar Airway Epithelium and Increased Within the Peribronchiolar Interstitium of Elf3-Deficient Mice During Repair Following Naphthalene-Induced Clara Cell Damage}

The pulmonary regenerative response to naphthaleneinduced Clara cell injury was examined by quantification of cell proliferation and mitosis within the distal bronchiolar airway epithelium and peribronchiolar interstitium of both Elf3 $+/+$ and Elf3- $/-$ mice. Immunohistochemical staining for Ki-67 was first performed in order to detect lung cell proliferation, and the data from male (Elf $3+/+$ and Elf3-/-) mice (Figure 4) are presented here first. In the bronchiolar airway epithelium, a low basal Ki-67 LI level of $\sim 5-8 \%$ was observed for both Elf3 $+/+$ and Elf3 $-I-$ mice within the uninjured day 0 and corn oil (control) groups (Figure $4 \mathrm{~m}$ ). In Elf3 $+/+$ mice, the Ki-67 LI had increased significantly above baseline control levels by day 2 , peaked at day 5 , and then returned to near baseline control levels by day 14 post naphthalene injection (Figure $4 \mathrm{~m}$ ). In Elf3-/- mice, however, the Ki-67 LI did not increase significantly above baseline control levels until day 5 , peaked at day 14 , and then returned to near baseline control levels by day 21 post naphthalene injection (Figure $4 \mathrm{~m}$ ). Furthermore, the Ki-67 LI measured within the bronchiolar epithelium of Elf3 $+/+$ mice was significantly higher than that of Elf3-/- mice at days 2 and 5 post naphthalene injection, whereas at day 14, the Ki-67 LI was significantly higher in Elf3-/- mice than in the Elf3 $+/+$ mice (Figure $4 \mathrm{~m}$ ). Collectively, these observations suggest delayed cell proliferation kinetics within the regenerating bronchiolar airway epithelium of Elf3-1mice when compared with Elf3 $+/+$ mice. Immunohistochemical staining for Ki-67 was also performed with female (Elf3 $+/+$ and Elf3-/-) mouse lung sections (Supplementary Figure S4a-l), and the overall trend, in which bronchiolar epithelial cell proliferation is delayed in Elf3-/mice, was conserved as shown with the LI data (Supplementary Figure S4m).

In the peribronchiolar interstitium of male (Elf3 $+/+$ and Elf3-/-) mice, a basal Ki-67 LI level of $\sim 11-15 \%$ was observed for the uninjured day 0 and corn oil (control) groups (Figure $4 \mathrm{n}$ ). In Elf3 $+1+$ mice, the Ki-67 LI had increased significantly above baseline control levels by day 1 , peaked at day 5 , and then returned to baseline control levels by day 21 post naphthalene injection (Figure $4 n$ ). In Elf3-/mice, the Ki-67 LI also increased significantly above baseline control levels at day 1 and peaked at day 5, but was still significantly higher than baseline control levels at day 21 post naphthalene injection (Figure $4 \mathrm{n}$ ). In addition, the Ki-67 LI measured within the peribronchiolar interstitium of Elf3 $-/-$ mice was significantly greater than that of Elf3 $+/+$ mice at almost all time points (ie, days 2-21) after treatment with naphthalene (Figure $4 \mathrm{n}$ ). Taken together, these data suggest that interstitial cell proliferation is augmented within the lungs of Elf3 $-/-$ mice when compared with Elf3 $+/+$ mice during repair following naphthalene-induced Clara cell ablation. The Ki-67 LI was also measured within the peribronchiolar interstitium of female (Elf3 $+/+$ and Elf3-/-) mice (Supplementary Figure S4n), and the results were consistent with that described above for the male mice.

In order to confirm the aforementioned differences in lung cell proliferation initially observed with the Ki-67 LI data, immunohistochemical staining for the mitosis marker $\mathrm{PH}-3$ was subsequently performed to determine the MI within the bronchiolar airway epithelium and peribronchiolar interstitium of both male (Elf3 $+/+$ and Elf3-I-) mice (Figure 5) and female (Elf3 $+/+$ and Elf3-/-) mice (Supplementary Figure S5). As expected, all of the findings obtained with the Ki-67 LI data were confirmed with the PH-3 MI data.

In order to better characterize the proliferating cells detected within the regenerating bronchiolar airway epithelium following naphthalene injury, triple immunofluorescent staining for the Clara cell marker CC10/CCSP, the ciliated cell marker $\beta$-Tubulin IV, and the cell proliferation marker Ki-67 was performed with lung sections from both male (Elf3 $+/+$ and Elf3-/-) mice (Figure 6) and female (Elf3 $+/+$ and Elf3-/-) mice (Supplementary Figure S6). As bronchiolar epithelial cell proliferation was at a maximum at days 5 and 14 post naphthalene injection in Elf3 $+/+$ mice and Elf3 $-1-$ mice, respectively, the data from the triple IF labeling analysis are presented for these two time points only. Many of the Ki-67-positive cells detected within the regenerating bronchiolar airway epithelium were dually 
positive for CC10/CCSP in both sexes of both Elf3 $+/+$ and Elf3-I- mice (Figure 6 and Supplementary Figure S6), suggesting that many of these proliferating bronchiolar epithelial cells are CC10/CCSP-expressing progenitor cells. Some CC10/CCSP-positive cells that were not dually positive for Ki-67 were also detected within the airway epithelium of both sexes of both Elf3 $+/+$ and Elf3- $/-$ mice (Figure 6 and Supplementary Figure S6), and these cells may represent nascent Clara cells that emerged as a result of the Clara cell regeneration occurring subsequent to the naphthaleneinduced injury. In addition, none of the $\beta$-Tubulin IVpositive cells detected within the airway epithelium were dually positive for Ki-67 in both sexes of both Elf3 $+/+$ and Elf3-I- mice (Figure 6 and Supplementary Figure S6), indicating that ciliated cells do not proliferate in response to naphthalene-induced Clara cell ablation.

\section{Elf3-Deficient Mice Express Reduced Levels of TGF- $\beta$ RII in the Bronchiolar Airway Epithelium During Both Steady-State and Repair After Naphthalene Injury}

As TGF- $\beta$ RII is a well-known transcriptional target gene of Elf3 and is involved in the induction of epithelial cell differentiation, ${ }^{26-30,37-39}$ we examined TGF- $\beta$ RII expression within the naphthalene injured and regenerating bronchiolar airway epithelium by performing immunofluorescent staining with lung sections from both male $($ Elf $3+/+$ and Elf3-/-) mice (Figure 7) and female (Elf3 $+/+$ and Elf3-/-) mice (Supplementary Figure S7). In order to quantify the amount of TGF- $\beta$ RII immunoreactivity, the fluorescent intensity of immunopositive signal was measured within the intact and undamaged bronchiolar airway epithelium and was expressed as the mean TGF- $\beta$ RII IF normalized to autofluorescence, as described in the Materials and methods. In both male and female Elf3 $+I+$ mice, the mean TGF- $\beta$ RII IF had increased significantly above day 0 and corn oil (control) levels at day 14 and then returned to near steady-state control levels by day 21 post naphthalene injection (Figure $7 \mathrm{~m}$ and Supplementary Figure $57 \mathrm{~m}$ ), indicating that expression of TGF- $\beta$ RII is induced within the regenerating and differentiating bronchiolar airway epithelium at approximately day 14 . In both male and female Elf3-I- mice, however, the mean TGF- $\beta$ RII IF remained at a low basal level and never changed significantly from control levels at all time points after treatment with naphthalene (Figure $7 \mathrm{~m}$ and Supplementary Figure $\mathrm{S} 7 \mathrm{~m}$ ), thus suggesting that Elf3 is involved in the induction of TGF- $\beta$ RII observed within the airway epithelium of Elf3 $+/+$ mice at day 14 . Furthermore, the mean TGF- $\beta$ RII IF was significantly lower in the airway epithelium of Elf3-/- mice when compared with Elf3 $+I+$ mice both basally (ie, at day 0 and after injection with corn oil) and at all time points after injection with naphthalene (Figure $7 \mathrm{~m}$ and Supplementary Figure S7m). Taken together, these findings potentially identify Elf3 as a major in vivo regulator of TGF- $\beta$ RII expression in the bronchiolar airway epithelium of the lung during both the steady-state and repair after naphthalene injury. However, the fact that TGF- $\beta$ RII expression was not completely absent and was detected at low levels within the airway epithelium of Elf3-1- mice suggests that other transcription factors may also be involved in regulating TGF- $\beta$ RII expression.

\section{DISCUSSION}

The principal aim of this study was to investigate the role of the epithelium-specific ETS transcription factor, Elf3, in regulating the process of airway epithelial regeneration following Clara cell-specific injury. Regulation of gene expression is a very important aspect of many physiological and pathological processes, and there have only been few studies examining the role of various transcription factors in the pulmonary regenerative response to naphthalene-induced Clara cell damage. ${ }^{4,6,9,33,40,41}$ In the present study, our findings suggest that Elf3 may play an important role in regulating airway epithelial repair kinetics, as the rate of bronchiolar epithelial cell proliferation and mitosis as well as Clara cell renewal was delayed in Elf3- $/$ - mice after treatment with naphthalene. The absence of Elf3 appeared to have no observable effect on the extent of Clara cell injury in Elf3- $/-$ mice, as there was no significant difference in the mean necrosis score between Elf3 $+1+$ and Elf3 $-/-$ mice at any time point after naphthalene exposure. Therefore, the observed differences in bronchiolar epithelial repair kinetics between Elf3 $+I+$ and Elf3- $-1-$ mice may not be because of differences in the extent of initial injury. This is a reasonable assumption, as Elf3 is not known to regulate the expression of genes, which encode for proteins involved in protection against the cytotoxicity of various xenobiotics. However, Elf3 has been shown to be involved in regulating the expression of genes involved in controlling epithelial cell proliferation and differentiation during embryonic/fetal development and oncogenesis. ${ }^{17,26,30,37,38,42-44}$ Therefore, the delayed kinetics of cell proliferation/mitosis and Clara cell reconstitution observed within the bronchiolar airway epithelium of Elf3-/ - mice is more likely because of changes in gene expression for proteins involved in regulating epithelial cell proliferation and/or differentiation during repair after naphthalene-induced Clara cell ablation. The best known candidate is the gene encoding for TGF- $\beta$ RII, as several studies have clearly shown that Elf3 can bind to the promoter and regulate transcription of the TGF- $\beta$ RII gene. ${ }^{27-29,37-39}$ Moreover, it has also been reported that Elf3- / - mice express reduced protein levels of TGF- $\beta$ RII in the developing small intestinal epithelium when compared with Elf3 $+/+$ mice. $^{26}$ Although TGF- $\beta$ RII is a potent inhibitor of cell proliferation, it is very important for the induction of epithelial cell differentiation. ${ }^{26,30}$ Interestingly, Elf3-/- mice also exhibit defective terminal differentiation of the small intestinal epithelium during fetal/neonatal development. ${ }^{26,30}$ In our study, we found that TGF- $\beta$ RII levels were significantly lower within the bronchiolar airway epithelium of Elf3 $-I-$ mice than within that of Elf3 $+/+$ 
mice during both the steady-state and regeneration after naphthalene injury. In addition, TGF- $\beta$ RII levels in Elf3 $+/+$ mice were significantly higher at day 14 post naphthalene injection than their respective steady-state control (day 0 and corn oil) levels, suggesting that expression of TGF- $\beta$ RII is induced during repair and differentiation (occurring around day 14) of the injured airway epithelium and that TGF- $\beta$ signaling may play an important role in this process. Furthermore, the fact that TGF- $\beta$ RII levels in Elf3-/- mice never significantly changed from their respective control levels at any time point after naphthalene exposure further strengthens the notion that Elf3 is a major player in the regulation of TGF- $\beta$ RII expression within the regenerating and differentiating airway epithelium. However, it must be acknowledged that although TGF- $\beta$ RII expression was substantially reduced in Elf3- $/-$ mice, it was not completely absent and could still be detected at low levels, thus suggesting that regulation of TGF- $\beta$ RII expression is very complex and other transcription factors may also be involved. It must also be recognized that although regeneration of the airway epithelium was delayed, Elf3-/mice eventually recovered with adequate Clara cell restitution by day 21 post naphthalene injury, further implying that other transcription factors involved in the injury-repair process may compensate for the absence of Elf3 in Elf3-/mice.

It should be acknowledged that in this study, we examined repair of the naphthalene-injured bronchiolar airway epithelium in both sexes (ie, male and female) of Elf $3+I+$ and Elf3-/- mice. Sex differences in naphthalene metabolism and naphthalene-induced Clara cell injury and subsequent repair have been well documented ${ }^{34,36}$ and, therefore, it is important to study these processes separately in male and/or female mice. In order to obtain an adequate understanding of any possible role for Elf3 in the pulmonary regenerative response to naphthalene-induced Clara cell depletion, we utilized both sexes of Elf3 $+/+$ and Elf3-I- mice, and all of the findings originally made in male (Elf3 $+/+$ and Elf3-I-) mice were also confirmed in female (Elf3 $+/+$ and Elf3-/-) mice. It must be discussed, however, that a major caveat of the Elf3-/ - mouse model utilized in this study is the absence of Elf3 during lung development. Thus, the possibility of compromised lung development in these Elf3-/- mice cannot be ruled out as it has been previously reported in the literature that Elf3 is highly expressed in the developing fetal mouse lung. ${ }^{22}$ Therefore, one cannot exclude the notion of a possible impairment of lung development resulting in a potential reduction of progenitor cells in adult Elf3-/- mice, which could play a role in the delayed repair kinetics observed in these mice following naphthalene injury. On the contrary, previous histological examination of fetal/postnatal lung tissue had failed to detect any gross abnormalities in Elf3- $/-$ mice ${ }^{26}$ thus suggesting no major defects of lung development in these mice. However, it is also possible that subtle defects in lung development may have not yet been uncovered in Elf3-/- mice. Future studies focused on examining progenitor cells during lung development in these Elf3-/- mice as well as airway epithelial repair after conditionally ablating Elf3 in adult mice are required in order to delineate these possibilities.

In this study, we also found significantly higher levels of cell proliferation and mitosis in the peribronchiolar interstitium of Elf3 $-/-$ mice than in Elf3 $+/+$ mice. This exaggerated level of cell proliferation/mitosis observed within the peribronchiolar interstitium of Elf3-/- mice may represent a compensatory mechanism due to the delayed kinetics of cell proliferation/mitosis within the bronchiolar epithelium. It has previously been shown that peribronchiolar interstitial cells can proliferate in response to naphthalene-induced Clara cell damage in mice. ${ }^{11,12}$ These proliferating interstitial cells are believed to be alveolar macrophages and fibroblast-like cells, and have been reported to interact with the basal lamina of adjacent bronchiolar epithelial cells during the repair process. ${ }^{11,12}$ Interestingly, delayed airway epithelial repair can promote fibroblast proliferation and fibrosis in other models of lung injury. ${ }^{45,46}$ In our study, histological analysis of Masson's trichrome staining did not show any evidence of pulmonary fibrosis in the lungs of both Elf3 $+/+$ and Elf3-I- mice after naphthalene exposure (data not shown). This is in agreement with the fact that this naphthalene-induced model of acute airway epithelial injury and subsequent repair is not normally associated with excessive inflammation or fibrosis. ${ }^{47}$ Therefore, we speculate that the vast amount of cell proliferation and mitosis detected within the peribronchiolar interstitium of Elf3-I- mice in our study may represent a facet of an exaggerated airway remodeling response occurring subsequent to the naphthalene-induced epithelial cell injury.

In the present study, we show that in both Elf $3+/+$ and Elf3-/- mice, ciliated cells remain undamaged and intact, and potentially play a role in temporarily covering and protecting the denuded basement membrane of the naphthalene-injured bronchiolar airway epithelium until completion of Clara cell regeneration. We also demonstrate that in both Elf3 $+/+$ and Elf3 $-/-$ mice, ciliated cells do not proliferate in response to naphthalene-induced Clara cell ablation. Although we used the ciliated cell marker, $\beta$-Tubulin IV, which is expressed relatively late in the differentiation of ciliated cells, others have also previously shown that ciliated cells do not proliferate during repair of the naphthalene-injured bronchiolar epithelium using the ciliated cell marker, FoxJ1, which is expressed earlier than $\beta$-Tubulin IV in the differentiation of ciliated cells. ${ }^{33}$ These findings are in accordance with a previous study, which utilized transgenic lineage tracing experiments in order to follow the fate of ciliated cells and provided strong evidence that ciliated cells do not proliferate or transdifferentiate into different epithelial cell types during repair of the naphthalene-injured mouse airway epithelium. ${ }^{10}$ In addition, we found that many of the proliferating (ie, Ki-67-positive) cells 
detected within the regenerating airway epithelium were also dually positive for CC10/CCSP in both Elf3 $+/+$ and Elf3-/ - mice. We speculate that these cells may represent a naphthalene-resistant sub-population of CC10/CCSPexpressing progenitor cells, which are also known as vCE cells. Others have previously characterized these vCE cells as immature progenitor and/or stem cells capable of simultaneously expressing CC10/CCSP and undergoing cell division, thereby contributing to the eventual reconstitution of mature and well-differentiated Clara cells within the bronchiolar airway epithelium following naphthalene injury. ${ }^{13,14}$ Furthermore, these vCE cells are harbored and maintained within a microenvironment or niche, which is provided by PNECs/NEBs through the paracrine secretion of various neuropeptides and bioactive amines. ${ }^{48}$ It has also previously been shown that acute naphthalene toxicity results in PNEC/NEB hyperplasia in mice, ${ }^{49}$ and after examination of PNECs/NEBs in our study, we found no observable difference in the extent of PNEC/NEB hyperplasia between Elf3 $+/+$ and Elf3-I- mice after naphthalene exposure (data not shown).

In summary, the data reported here from this study clearly show that Elf3 plays an important role in regulating bronchiolar airway epithelial repair kinetics following Clara cell-specific injury and ablation. These findings potentially indicate a possible involvement of Elf3 in regulating gene expression in the context of repair occurring in response to airway inflammation and subsequent epithelial injury in the setting of various pulmonary diseases, such as asthma and chronic obstructive pulmonary disease. In addition, the findings obtained from this study contribute to the field of ETS biology by revealing a novel role for the epitheliumspecific ETS transcription factor, Elf3, in controlling airway epithelial cell differentiation. These findings are also unique when compared with previous studies utilizing knockout mouse models for other ETS genes in which no epithelial defects have been described. ${ }^{50}$ Although a defect in terminal differentiation of the small intestinal epithelium during embryonic development has previously been demonstrated in Elf3- $/-$ mice ${ }^{26}$ this is the first study to describe abnormal kinetics of cell proliferation and differentiation during repair of the injured bronchiolar epithelium in these mice. The cellular and molecular mechanisms of airway epithelial regeneration and repair are very complex and have been studied extensively in several laboratories; however, further studies are required in order to elucidate the exact role of Elf3 and other ETS transcription factors in this process.

Supplementary Information accompanies the paper on the Laboratory Investigation website (http://www.laboratoryinvestigation.org)

\section{ACKNOWLEDGEMENTS}

This work was supported in part by operating grants from the Canadian Institutes of Health Research (no. MOP-97779) and from the Canadian Cystic Fibrosis Foundation to $\mathrm{JH}$. JRO is a recipient of the Canadian Institutes of Health Research Canada Graduate Scholarships Doctoral Award.

\section{DISCLOSURE/CONFLICT OF INTEREST}

The authors declare no conflict of interest.

1. Rawlins EL, Hogan BL. Epithelial stem cells of the lung: privileged few or opportunities for many? Development 2006;133:2455-2465.

2. Hong KU, Reynolds SD, Watkins $S$, et al. Basal cells are a multipotent progenitor capable of renewing the bronchial epithelium. Am J Pathol 2004;164:577-588.

3. Hong KU, Reynolds SD, Watkins S, et al. In vivo differentiation potential of tracheal basal cells: evidence for multipotent and unipotent subpopulations. Am J Physiol Lung Cell Mol Physiol 2004;286:L643L649.

4. Linnoila RI, Jensen-Taubman S, Kazanjian A, et al. Loss of GFI1 impairs pulmonary neuroendorine cell proliferation, but the neuroendocrine phenotype has limited impact on post-naphthalene airway repair. Lab Invest 2007;87:336-344.

5. Poulsen $\pi$, Naizhen $X$, Poulsen HS, et al. Acute damage by naphthalene triggers expression of the neuroendocrine marker PGP9.5 in airway epithelial cells. Toxicol Lett 2008;181:67-74.

6. Jensen-Taubman S, Wang XY, Linnoila RI. Achaete-scute homologue-1 tapers neuroendocrine cell differentiation in lungs after exposure to naphthalene. Toxicol Sci 2010;117:238-248.

7. Giangreco A, Reynolds SD, Stripp BR. Terminal bronchioles harbor a unique airway stem cell population that localizes to the bronchoalveolar duct junction. Am J Pathol 2002;161:173-182.

8. Kim CF, Jackson EL, Woolfenden $A E$, et al. Identification of bronchioalveolar stem cells in normal lung and lung cancer. Cell 2005;121:823-835.

9. Park KS, Wells JM, Zorn AM, et al. Transdifferentiation of ciliated cells during repair of the respiratory epithelium. Am J Respir Cell Mol Biol 2006;34:151-157.

10. Rawlins EL, Ostrowski LE, Randell SH, et al. Lung development and repair: contribution of the ciliated lineage. Proc Natl Acad Sci USA 2007;104:410-417.

11. Van Winkle LS, Buckpitt AR, Nishio SJ, et al. Cellular response in naphthalene-induced Clara cell injury and bronchiolar epithelial repair in mice. Am J Physiol 1995;269:L800-L818.

12. Van Winkle LS, Isaac JM, Plopper CG. Distribution of epidermal growth factor receptor and ligands during bronchiolar epithelial repair from naphthalene-induced Clara cell injury in the mouse. Am J Pathol 1997;151:443-459.

13. Reynolds SD, Giangreco A, Power JH, et al. Neuroepithelial bodies of pulmonary airways serve as a reservoir of progenitor cells capable of epithelial regeneration. Am J Pathol 2000;156:269-278.

14. Hong KU, Reynolds SD, Giangreco A, et al. Clara cell secretory proteinexpressing cells of the airway neuroepithelial body microenvironment include a label-retaining subset and are critical for epithelial renewal after progenitor cell depletion. Am J Respir Cell Mol Biol 2001;24: 671-681.

15. Rawlins EL, Okubo T, Xue Y, et al. The role of Scgb1a1+ Clara cells in the long-term maintenance and repair of lung airway, but not alveolar, epithelium. Cell Stem Cell 2009;4:525-534.

16. Oikawa T, Yamada T. Molecular biology of the Ets family of transcription factors. Gene 2003;303:11-34.

17. Kageyama $S$, Liu $H$, Nagata $M$, et al. The role of ETS transcription factors in transcription and development of mouse preimplantation embryos. Biochem Biophys Res Commun 2006;344:675-679.

18. Turner DP, Findlay VJ, Moussa O, et al. Defining ETS transcription regulatory networks and their contribution to breast cancer progression. J Cell Biochem 2007;102:549-559.

19. Lacorazza HD, Nimer SD. The emerging role of the myeloid Elf-1 like transcription factor in hematopoiesis. Blood Cells Mol Dis 2003;31: 342-350.

20. Randi AM, Sperone A, Dryden NH, et al. Regulation of angiogenesis by ETS transcription factors. Biochem Soc Trans 2009;37:1248-1253.

21. Oettgen P. Regulation of vascular inflammation and remodeling by ETS factors. Circ Res 2006;99:1159-1166.

22. Tymms MJ, Ng AY, Thomas RS, et al. A novel epithelial-expressed ETS gene, ELF3: human and murine CDNA sequences, murine genomic organization, human mapping to 1q32.2 and expression in tissues and cancer. Oncogene 1997;15:2449-2462. 
23. Oettgen $\mathrm{P}$, Alani RM, Barcinski MA, et al. Isolation and characterization of a novel epithelium-specific transcription factor, ESE-1, a member of the ets family. Mol Cell Biol 1997;17:4419-4433.

24. Grall F, Gu X, Tan L, et al. Responses to the proinflammatory cytokines interleukin-1 and tumor necrosis factor alpha in cells derived from rheumatoid synovium and other joint tissues involve nuclear factor kappa B-mediated induction of the Ets transcription factor ESE-1. Arthritis Rheum 2003;48:1249-1260.

25. Rudders S, Gaspar J, Madore R, et al. ESE-1 is a novel transcriptional mediator of inflammation that interacts with NF-kappa B to regulate the inducible nitric-oxide synthase gene. J Biol Chem 2001;276:33023309 .

26. $\mathrm{Ng} \mathrm{AY,} \mathrm{Waring} \mathrm{P}$, Ristevski $\mathrm{S}$, et al. Inactivation of the transcription factor Elf3 in mice results in dysmorphogenesis and altered differentiation of intestinal epithelium. Gastroenterology 2002;122: 1455-1466.

27. Kim $\mathrm{JH}$, Wilder $\mathrm{PJ}, \mathrm{Hou} \mathrm{J}$, et al. Activation of the murine type II transforming growth factor-beta receptor gene: up-regulation and function of the transcription factor Elf-3/Ert/Esx/Ese-1. J Biol Chem 2002;277:17520-17530.

28. Agarkar VB, Babayeva ND, Rizzino A, et al. Preliminary crystallographic analysis of mouse Elf3 C-terminal DNA-binding domain in complex with type II TGF-beta receptor promoter DNA. Acta Crystallogr Sect F Struct Biol Cryst Commun 2009;65:1261-1263.

29. Agarkar VB, Babayeva ND, Wilder PJ, et al. Crystal structure of mouse Elf3 C-terminal DNA-binding domain in complex with type II TGF-beta receptor promoter DNA. J Mol Biol 2010;397:278-289.

30. Flentjar N, Chu PY, Ng AY, et al. TGF-betaRIl rescues development of small intestinal epithelial cells in Elf3-deficient mice. Gastroenterology 2007;132:1410-1419.

31. Wu J, Duan R, Cao $\mathrm{H}$, et al. Regulation of epithelium-specific Ets-like factors ESE-1 and ESE-3 in airway epithelial cells: potential roles in airway inflammation. Cell Res 2008;18:649-663.

32. Zhao Y, Gilmore BJ, Young SL. Expression of transforming growth factor-beta receptors during hyperoxia-induced lung injury and repair. Am J Physiol 1997;273:L355-L362.

33. Kida $H$, Mucenski ML, Thitoff AR, et al. GP130-STAT3 regulates epithelial cell migration and is required for repair of the bronchiolar epithelium. Am J Pathol 2008;172:1542-1554.

34. Oliver JR, Kushwah R, Wu J, et al. Gender differences in pulmonary regenerative response to naphthalene-induced bronchiolar epithelial cell injury. Cell Prolif 2009;42:672-687.

35. Chen P, McGuire JK, Hackman RC, et al. Tissue inhibitor of metalloproteinase-1 moderates airway re-epithelialization by regulating matrilysin activity. Am J Pathol 2008;172:1256-1270.

36. Van Winkle LS, Gunderson AD, Shimizu JA, et al. Gender differences in naphthalene metabolism and naphthalene-induced acute lung injury. Am J Physiol Lung Cell Mol Physiol 2002;282 L1122-L1134.

37. Chang J, Lee $C$, Hahm KB, et al. Over-expression of ERT(ESX/ESE-1/ ELF3), an ets-related transcription factor, induces endogenous TGFbeta type II receptor expression and restores the TGF-beta signaling pathway in Hs578t human breast cancer cells. Oncogene 2000;19: 151-154.

38. Lee HJ, Chang JH, Kim YS, et al. Effect of ets-related transcription factor (ERT) on transforming growth factor (TGF)-beta type II receptor gene expression in human cancer cell lines. J Exp Clin Cancer Res 2003; 22:477-480.

39. Kopp JL, Wilder PJ, Desler $M$, et al. Unique and selective effects of five Ets family members, Elf3, Ets1, Ets2, PEA3, and PU.1, on the promoter of the type II transforming growth factor-beta receptor gene. J Biol Chem 2004;279:19407-19420.

40. Zhang Y, Goss AM, Cohen ED, et al. A Gata6-Wnt pathway required for epithelial stem cell development and airway regeneration. Nat Genet 2008:40:862-870.

41. Zemke AC, Teisanu RM, Giangreco $A$, et al. beta-Catenin is not necessary for maintenance or repair of the bronchiolar epithelium. Am J Respir Cell Mol Biol 2009;41:535-543.

42. Jedlicka P, Gutierrez-Hartmann A. Ets transcription factors in intestina morphogenesis, homeostasis and disease. Histol Histopathol 2008;23:1417-1424.

43. Yoshida N, Yoshida S, Araie M, et al. Ets family transcription factor ESE1 is expressed in corneal epithelial cells and is involved in their differentiation. Mech Dev 2000;97:27-34.

44. Kwon MC, Koo BK, Kim YY, et al. Essential role of CR6-interacting factor 1 (Crif1) in E74-like factor 3 (ELF3)-mediated intestinal development. J Biol Chem 2009;284:33634-33641.

45. Adamson IY, Young L, Bowden DH. Relationship of alveolar epithelial injury and repair to the induction of pulmonary fibrosis. Am J Pathol 1988;130:377-383.

46. Adamson IY, Hedgecock C, Bowden DH. Epithelial cell-fibroblast interactions in lung injury and repair. Am J Pathol 1990 137:385-392.

47. Atkinson JJ, Toennies HM, Holmbeck K, et al. Membrane type 1 matrix metalloproteinase is necessary for distal airway epithelial repair and keratinocyte growth factor receptor expression after acute injury. Am J Physiol Lung Cell Mol Physiol 2007;293:L600-L610.

48. Linnoila RI. Functional facets of the pulmonary neuroendocrine system. Lab Invest 2006;86:425-444.

49. Stevens TP, McBride JT, Peake JL, et al. Cell proliferation contributes to PNEC hyperplasia after acute airway injury. Am J Physiol 1997;272: L486-L493.

50. Bartel FO, Higuchi T, Spyropoulos DD. Mouse models in the study of the Ets family of transcription factors. Oncogene 2000;19:6443-6454. 